\title{
Hepatic Resection Followed by Hepatic Arterial Infusion Chemotherapy for Hepatocellular Carcinoma with Intrahepatic Dissemination
}

\author{
KUNITAKA KURAMOTO ${ }^{1,2}$, TORU BEPPU ${ }^{1,2}$, HIDETOSHI NITTA $^{1}$, KATSUNORI IMAI $^{1}$, \\ TOSHIRO MASUDA $^{1}$, TATSUNORI MIYATA ${ }^{1}$, YUKI KOGA ${ }^{1,2}$, YUKI KITANO ${ }^{1}$, TAKAYOSHI KAIDA ${ }^{1}$, \\ SHIGEKI NAKAGAWA ${ }^{1}$, HIROHISA OKABE ${ }^{1}$, HIROMITSU HAYASHI ${ }^{1}$, DAISUKE HASHIMOTO ${ }^{1}$, \\ YO-ICHI YAMASHITA ${ }^{1}$, AKIRA CHIKAMOTO ${ }^{1}$, KEN KIKUCHI $^{3}$ and HIDEO BABA ${ }^{1}$ \\ ${ }^{1}$ Department of Gastroenterological Surgery, Graduate School of Life Sciences, \\ Kumamoto University, Kumamoto, Japan; \\ ${ }^{2}$ Department of Surgery, Yamaga City Medical Center, Kumamoto, Japan; \\ ${ }^{3}$ Medical Quality Management Center, Kumamoto University Hospital, Kumamoto, Japan
}

\begin{abstract}
Background/Aim: To investigate the utility of adjuvant hepatic arterial infusion chemotherapy (HAIC) following hepatectomy for patients with hepatocellular carcinoma (HCC) with intrahepatic dissemination (IHD) after local ablation therapy. Patients and Methods: Twelve patients with HCC with IHD were divided into two groups: HAIC group ( $n=6)$ underwent hepatectomy followed by HAIC; and the non-HAIC group $(n=6)$ underwent hepatectomy alone. HAIC with cisplatin and 5-fluorouracil was started within a month and was continued for a month: Results: At the first local ablation, tumors close to the major portal vein and insufficient ablation were recognized in eight $(67.7 \%)$ and six (58.3\%) of the patients, respectively. In the HAIC group, the 1-, 3-, and 5-year disease-free and overall survival rates were $50.0 \%, 16.7 \%$, and $16.7 \%$, and $83.3 \%$, $83.3 \%$ and $62.5 \%$, respectively. Three patients in the HAIC group remain alive after 10 years of follow-up. Conclusion: Hepatic resection with short-term postoperative HAIC may provide excellent outcomes in patients with HCC and IHD.
\end{abstract}

Local ablation therapy (LAT) has developed worldwide as one of the standard treatments for hepatocellular carcinoma

Correspondence to: Hideo Baba, Professor of Department of Gastroenterological Surgery, Graduate School of Life Sciences, Kumamoto University, 1-1-1 Honjo, chuo-Ku, Kumamoto 8608556, Japan. Tel: +81 963735211, Fax: +81 963714378, e-mail: hdobaba@kumamoto-u.ac.jp

Key Words: Hepatocellular carcinoma, intrahepatic dissemination, local ablation therapy, portal vein tumor thrombosis, hepatic arterial infusion chemotherapy.
(HCC) (1-6), AT includes percutaneous ethanol injection therapy, radiofrequency ablation (RFA), microwave coagulation therapy (MCT), and cryoablation. LAT is a curative and less invasive treatment limited to small-sized HCC; however, several critical patterns of recurrence after LAT have been reported, including local recurrence with vascular invasion, intrahepatic dissemination (IHD), extrahepatic metastasis, and neoplastic seeding (7-17). These critical recurrences certainly lead to a poor prognosis even after curative treatment $(18,19)$. Among them, IHD is one of the most serious problems (9-14).

Macroscopic venous invasion is one of the strongest risk factors for early recurrence and is associated with poor prognosis after hepatic resection in patients with HCC (20, 21 ). For these patients, various non-surgical, surgical, and combined treatments have been reported; however, there are insufficient data regarding long-term outcomes (22). In contrast, the Liver Cancer Study Group of Japan clearly demonstrated that hepatic resection can provide a longer survival outcome than non-surgical treatment if portal vein tumor thrombus (PVTT) is limited to the first-order portal branches (23). Recently, we demonstrated a novel adjuvant regimen for hepatic arterial infusion chemotherapy (HAIC) that may reduce the risk of recurrence after hepatectomy for patients with HCC with macroscopic PVTT (24). Patients with high-grade vascular invasion are good candidates for adjuvant HAIC. Some reports have demonstrated the similar usefulness of adjuvant therapy, but none of these were randomized controlled trials; therefore, their results were not conclusive (25-27).

IHD is a highly malignant status of aggressive recurrence; therefore, we have been applying HAIC for patients with IHD. This study aimed to determine the utility of additional 
HAIC after hepatectomy in patients with IHD in terms of recurrence and long-term prognosis.

\section{Patients and Methods}

Between April 1997 and March 2012, 77 patients underwent hepatic resection for HCC with macroscopic vascular invasion and no distant metastasis at Kumamoto University Hospital. Twelve of these patients who had IHD were enrolled in this study. IHD was defined as a pattern of recurrence after LAT with numerous intrahepatic metastases, mainly in the treated section, together with segmental or sectional PVTT (13). The invasion sites of PVTT were defined as follows: Vp2, second-order branch of the portal vein; $\mathrm{Vp} 3$, first-order branch of the portal vein; and $\mathrm{Vp} 4$, main trunk or opposite first-order branch (28). PVTT was diagnosed by preoperative dynamic computed tomography (CT) or magnetic resonance imaging (MRI) and CT angiography. Histopathological examinations of the resected specimens showed HCC in all cases. The inclusion criteria for HAIC were as follows: no recurrence apparent on 1-month postoperative CT angiography, sufficient liver functional reserve, good performance status, and adequate postoperative recovery. This study was conducted according to the Declaration of Helsinki and the ethical guidelines for clinical studies from the Ministry of Health, Labour and Welfare in Japan. The Institutional Review Board of the Kumamoto University approved this study (approval number 1274). Written informed consent was obtained from all participating patients.

Surgical technique. Operative details of the hepatic resection were described in a previous report (29). Briefly, parenchymal transection was performed using an ultrasonic surgical aspirator (CUSA; Valley Lab, Boulder, CO, USA) and bipolar forceps with intermittent clamping of the hepatoduodenal ligament. From 2005, we started to use the precoagulation technique using the VIO soft coagulation system (ERBE, Elektromedizin GmbH, Tübingen, Germany) (30). For patients with Vp4, PVTT was isolated using the 'peeling off' technique (31).

HAIC treatment. Details of HAIC were described in a previous report (24). Briefly, we used two different protocols for HAIC. From 1997 to 2007, the patients were treated with HAIC using a subcutaneously implanted reservoir via the femoral artery (old protocol). One course consisted of cisplatin $(10 \mathrm{mg}$ daily on days 1-5) followed by an infusion of 5-fluorouracil (5-FU; $250 \mathrm{mg}$ daily on days 1-5) with two days' rest. HAIC was started within one month and repeated for three courses. Since 2007, HCC patients have been treated with one-shot HAIC (new protocol). Cisplatin (60 $\left.\mathrm{mg} / \mathrm{m}^{2}\right)$ followed by $5-\mathrm{FU}\left(600 \mathrm{mg} / \mathrm{m}^{2}\right)$ was injected into the adequate hepatic artery, which was followed by mytomycin C (3 $\mathrm{mg} / \mathrm{m}^{2}$ ) dissolved in degradable starch microspheres (DSM; Spherex; Yakult Co., Tokyo, Japan). The new protocol was started within one month after hepatectomy and repeated twice with a 1-month interval.

Follow-up. The follow-up program included monitoring of three tumor markers, serum $\alpha$-fetoprotein (AFP), and protein induced by vitamin $\mathrm{K}$ absence or antagonist-II (PIVKA-II) assay every 1 to 2 months. Diagnostic imaging was performed every 3 to 4 months by abdominal ultrasonography, enhanced CT, or MRI. If recurrence was recognized during follow-up, the patient underwent repeat hepatectomy, RFA, transarterial chemoembolization (TACE), radiotherapy, or chemotherapy (32).
Statistical analyses. Student's $t$-test, chi-square test, or Fisher's exact test was used to evaluate the clinical and histological values. The starting point of disease-free survival (DFS) and overall survival (OS) was the date of hepatic resection for IHD. Cumulative survival curves were calculated using the Kaplan-Meier method and were statistically compared using the log-rank test. For all tests, a $p$-value of less than 0.05 was considered statistically significant.

\section{Results}

The clinical characteristics of 12 patients with HCC with IHD at an initial LAT are summarized in Table I. All tumors were $3 \mathrm{~cm}$ in size or less, most patients had a single nodule and almost all tumors (11/12) were hypervascular. There were 11 tumors of the simple nodular type and there was one simple nodular tumor with extra-nodular growth type HCC. HCCs adjacent to the main or sectional portal vein were found in eight (67.7\%) patients, and seven (58.3\%) patients had insufficient ablation (therapeutic effect; TE3 in three and TE4b in four) using the therapeutic effect evaluation by Liver Cancer Study Group of Japan (33). For initial LAT procedures, two, three, and seven patients underwent percutaneous ethanol injection, MCT, and RFA, respectively. Patients had similar pre-LAT and pre-hepatectomy liver function values; however, the degree of tumor progression was significantly more advanced (Table II).

The reasons that patients in the non-HAIC group did not receive HAIC were as follows: early recurrence in one, refusal of therapy in two, comorbidities in one, and poor performance status in two. According to our treatment strategy, one patient with multiple and hypervascular tumor recurrence in the remnant liver by postoperative 1-month CT angiography was treated with TACE using cisplatin suspended in lipiodol with a gelatin sponge instead of HAIC (34).

HAIC and non-HAIC groups were compared on the basis of their perioperative clinical characteristics (Table III). There were no significant differences between the two groups in preoperative, surgical, and pathological variables. The new and old protocols were followed in three and nine patients, respectively. All patients completed adjuvant HAIC as initially planned, and no major complications were observed after hepatic resection nor after HAIC. No patient died within 1 month after hepatectomy. The median duration between the initial LAT and hepatic resection for IHD was 14.5 (range $=3-43$ ) months.

Survival outcome. The cumulative survival curves of DFS and OS for patients overall are shown in Figure 1. The 1-, 3-, 5-year survival rates and the median survival times (MST) were $41.7 \%, 16.7 \%, 16.7 \%$ and 3.0 months for DFS and $66.7 \%$, $58.3 \%, 48.6 \%$ and 45.2 months for OS, respectively. The cumulative survival curves were compared in the two groups (Figure 2). The mean follow-up period was 80.4 months (range=3.0-140.5 months) and 29.4 months (range=3.2-70.9 
Table I. The clinical characteristics of 12 patients with hepatocellular carcinoma with intrahepatic dissemination (IHD) at an initial local ablation therapy (LAT).

\begin{tabular}{|c|c|c|c|c|c|c|c|c|}
\hline Case & $\begin{array}{l}\text { Tumor } \\
\text { diameter } \\
(\mathrm{mm})\end{array}$ & $\begin{array}{l}\text { Tumor } \\
\text { number }\end{array}$ & Hypervascularity & $\begin{array}{l}\text { Gross } \\
\text { type }\end{array}$ & $\begin{array}{l}\text { Close to } \\
\text { Glissonean } \\
\text { capsule }\end{array}$ & $\begin{array}{c}\text { Therapeutic } \\
\text { effects }\end{array}$ & $\begin{array}{l}\text { LAT } \\
\text { method }\end{array}$ & $\begin{array}{c}\text { Interval to } \\
\text { IHD } \\
\text { (months) }\end{array}$ \\
\hline 1 & 30 & 1 & Yes & SN & Yes & TE3 & PEIT+RFA & 18 \\
\hline 2 & 20 & 1 & Yes & SN & No & TE4a & PEIT & 29 \\
\hline 3 & 15 & 1 & Yes & $\mathrm{SN}$ & Yes & TE4a & MCT & 22 \\
\hline 4 & 25 & 1 & Yes & SN & No & $\mathrm{TE} 4 \mathrm{~b}$ & PEIT & 22 \\
\hline 5 & 20 & 1 & Yes & SN & Yes & TE4a & MCT & 10 \\
\hline 6 & 15 & 1 & Yes & SN & Yes & $\mathrm{TE} 4 \mathrm{~b}$ & RFA & 27 \\
\hline 7 & 15 & 2 & Yes & $\mathrm{SN}$ & No & TE3 & MCT & 3 \\
\hline 8 & 30 & 2 & Yes & SNEG & Yes & TE3 & RFA & 9 \\
\hline 9 & 29 & 1 & Yes & SN & Yes & TE4b & RFA & 43 \\
\hline 10 & 25 & 1 & Yes & SN & Yes & TE4b & RFA & 11 \\
\hline 11 & 23 & 1 & Yes & SN & Yes & TE4a & RFA & 9 \\
\hline 12 & 25 & 1 & no & SN & No & TE4a & RFA & 11 \\
\hline
\end{tabular}

TE, Therapeutic effect evaluation by Liver Cancer Study Group of Japan (33); SN, simple nodular type; SNEG, simple nodular with extra-nodular growth; PEIT, percutaneous ethanol injection therapy; RFA, radiofrequency ablation; MCT, microwave coagulation therapy.

Table II. Clinical profile and serological assays for patients with hepatocellular carcinoma with intrahepatic dissemination treated with hepatic resection $(n=12)$.

\begin{tabular}{|c|c|c|c|c|}
\hline \multicolumn{2}{|l|}{ Factor } & \multirow{2}{*}{$\frac{\text { Pre-LAT }}{68.0(51-79)}$} & \multirow{2}{*}{$\begin{array}{c}\text { Pre-hepatectomy } \\
68.5(52-79)\end{array}$} & \multirow{2}{*}{$\frac{p \text {-Value }}{<0.001}$} \\
\hline Age, years & Median (range) & & & \\
\hline Gender, n & Male/female & $10 / 2$ & - & - \\
\hline Hepatitis, $n$ & HBsAg+/HCVAb+/both +/both -) & $6 / 3 / 0 / 3$ & - & - \\
\hline Child-Pugh grade, $\mathrm{n}$ & $\mathrm{A} / \mathrm{B}$ & $12 / 0$ & $11 / 1$ & 0.23 \\
\hline Tumor diameter, $\mathrm{mm}$ & Median (range) & $21.2(12-30)$ & $43.3(25-70)$ & 0.02 \\
\hline Tumor number, $\mathrm{n}$ & Solitary/multiple & $10 / 2$ & $0 / 12$ & $<0.001$ \\
\hline Macroscopic PVTT, n & Yes/no & $0 / 12$ & $12 / 0$ & $<0.001$ \\
\hline Extrahepatic metastasis, $\mathrm{n}$ & Yes/no & $0 / 12$ & $0 / 12$ & - \\
\hline $\mathrm{AFP}, \mathrm{ng} / \mathrm{ml}$ & Median (range) & $15.1(4.7-2818)$ & $207.55(3.9-9252)$ & 0.18 \\
\hline PIVKA-II, mAU/ml & Median (range) & $20(3.1-1759)$ & $168(15-1432)$ & 0.32 \\
\hline
\end{tabular}

HBs-Ag, Hepatitis B surface antigen; HCV-Ab, hepatitis C virus antibody; PVTT, portal vein tumor thrombus; AFP, alpha-fetoprotein; PIVKA-II, protein induced by vitamin $\mathrm{K}$ absence or antagonists-II.

months) in the HAIC and the non-HAIC groups, respectively. The 1-, 3-, 5-year DFS rates and the median DFS were 50.0\%, $16.7 \%, 16.7 \%$, and 7.9 months in the HAIC group and $33.3 \%$, $16.7 \%, 16.7 \%$, and 2.5 months in the non-HAIC group, respectively. The DFS rates $(p=0.55)$ and the OS rates $(p=0.18)$ showed no significant differences in the two groups. The 1-, 3-, 5- year OS rates and the MST were 83.3\%, 83.3\%, 62.5\%, and over 120 months in the HAIC group and 50.0\%, 33.3\%, $33.3 \%$ and 11.7 months in the non-HAIC group, respectively. In the HAIC group, there were three 10-year survivors.

Initial site and time of recurrence was investigated. Intrahepatic recurrence within 2 years was observed in $3 / 6$ $(50 \%)$ and $5 / 6(83.3 \%)$ patients in the HAIC and non-HAIC groups, respectively. The rates of recurrence with PVTT were identical in the two groups $(66.7 \%)$. One patient in the HAIC group was diagnosed as having a solitary recurrence after 10 years; therefore, the patient was diagnosed as having multicentric HCC. This patient was treated with RFA. The other patients with intrahepatic metastasis received TACE or HAIC. As a distant metastasis, adrenal metastasis was observed after 26 months in the HAIC group.

\section{Discussion}

Various types of LAT can cause IHD if the tumor ablated is located near the major Glissonean pedicle or if surgical margins are insufficient (13). In such patients, microscopic invasion around the periphery of the tumor may have been insufficiently 
Table III. Perioperative clinical characteristics of patients with hepatocellular carcinoma who underwent hepatic resection: HAIC group versus non-HAIC group.

\begin{tabular}{|c|c|c|c|c|}
\hline & & HAI group $(n=6)$ & Non-HAI group $(n=6)$ & $p$-Value \\
\hline Age, years & Median (range) & $69.8 \pm 9.8$ & $65.8 \pm 6.6$ & 0.72 \\
\hline Gender, $\mathrm{n}$ & Male/female & $6 / 0$ & $4 / 2$ & 0.07 \\
\hline Hepatitis, $n$ & HBsAg+/HCVAb+/both +/both -) & $4 / 1 / 0 / 1$ & $2 / 2 / 0 / 2$ & 0.42 \\
\hline Platelet count, $\times 10^{4} / \mu \mathrm{l}$ & Mean \pm SD & $10.4 \pm 4.6$ & $10.0 \pm 3.2$ & 0.49 \\
\hline Child-Pugh grade, $\mathrm{n}$ & $\mathrm{A} / \mathrm{B}$ & $6 / 0$ & $5 / 1$ & 0.93 \\
\hline ICGR $15, \%$ & Mean \pm SD & $14.2 \pm 4.2$ & $21.3 \pm 8.2$ & 0.17 \\
\hline $\mathrm{AFP}, \mathrm{ng} / \mathrm{ml}$ & Mean \pm SD & $1806(11-3775)$ & $1431(3.9-7518)$ & 0.95 \\
\hline AFP-L3 & $\geq 10 \% /<10 \%$ & $3 / 3$ & $3 / 3$ & 1.00 \\
\hline PIVKA-II, mAU/ml & & $818.5(15-2694)$ & $195.5(62-592)$ & 0.36 \\
\hline Tumor diameter, $\mathrm{mm}$ & Median (range) & $39.5 \pm 15.7$ & $44.3 \pm 18.0$ & 0.60 \\
\hline Multiple tumors & Yes/no & $4 / 2$ & $4 / 2$ & 1.00 \\
\hline Operative time, $\min$ & Mean \pm SD & $515.8 \pm 63.2$ & $400 \pm 112$ & 0.11 \\
\hline Blood loss, $\mathrm{ml}$ & Mean \pm SD & $973.3 \pm 614$ & $886 \pm 730$ & 0.81 \\
\hline Blood transfusion & Yes/no & $2 / 4$ & $2 / 4$ & 1.00 \\
\hline Type of resection & Major/minor & $5 / 1$ & $2 / 4$ & 0.07 \\
\hline Tumor differentiation & Well to moderate/poor/unknown & $3 / 3 / 0$ & $2 / 3 / 1$ & 0.05 \\
\hline Tumor type & Massive/diffuse (simple nodular/other) & $1 / 5$ & $0 / 6$ & 0.99 \\
\hline Surgical margin & Negative/positive & $6 / 0$ & $6 / 0$ & 1.00 \\
\hline Portal venous invasion & $\mathrm{Vp} 0-1 / 2 / 3 / 4$ & $2 / 1 / 3 / 0$ & $3 / 1 / 2 / 0$ & 0.57 \\
\hline Hepatic venous invasion & Vv0-1/2/3 & $1 / 5 / 0$ & $0 / 6 / 0$ & 0.99 \\
\hline
\end{tabular}

HAIC, Hepatic arterial infusion chemotherapy; HBs-Ag, hepatitis B surface antigen, HCV-Ab, hepatitis C virus antibodies, ICG-R15, indocyanine green retention rate at $15 \mathrm{~min}$; AFP, alpha-fetoprotein; PIVKA-II, protein induced by vitamin $\mathrm{K}$ absence or antagonists-II. Vessel invasion was assessed with criteria of the Liver Cancer Study Group of Japan (28).

ablated $(35,36)$. Patients with IHD often have multiple tumors, macroscopic portal invasion, and poorly differentiated tumor components (7-14). Among these factors, macroscopic portal invasion is the most significant poor prognostic factor after hepatic resection $(20,21)$. For patients with HCC with macroscopic portal invasion, surgical therapy demonstrated a better outcome than nonsurgical therapy. The MSTs of patients after hepatic resection as monotherapy and surgical multidisciplinary treatment were 10 (range=6.0-20.0) months and 16 (range=9.5-22.1) months, respectively (22). A recent national Japanese survey confirmed that patients with HCC with Child-Pugh A disease and PVTT had a significantly longer MST in the hepatectomy-treated group than in the nonsurgicallytreated group $(2.45$ vs. 1.57 years; $p<0.001)$ in a propensity score-matched cohort (23). In the current study, patients with IHD in the HAIC-treated group had a higher median diseasefree survival, but not significantly so, than those of the nonHAIC group (7.9 vs. 2.5 months). Five out of six patients with IHD without HAIC had recurrent disease and died within 2 years. In contrast, three patients with HAIC survived for more than 10 years. The rate of intrahepatic recurrence within 2 years was lower in the HAIC-treated group, but not significant $(50 \%$ vs. $83.3 \%$ ). Postoperative intrahepatic recurrence instead of multicentric occurrence is mainly recognized within 2 years (37). HAIC may be effective for patients with IHD with high malignant potential. IHD was found to be significantly associated with the epithelial-mesenchymal transition, which can promote massive invasion of HCC cells (38-40). Additionally, expression of hypoxia-inducible factor- 1 and epithelial cell adhesion molecule can promote aggressive phenotype after LAT (41). Our previous study identified that patients with macroscopic PVTT treated with hepatectomy and adjuvant HAIC can have better 5-year DFS compared to those not those with HAIC (33.1\% vs. $11.8 \%$ ), even though the former included a larger number of patients with poorly differentiated tumors (24). Moreover, HAIC after hepatectomy is effective only for $\mathrm{Vp} 3$ or $\mathrm{Vp} 4$ grade disease, not for $\mathrm{Vp} 2$. Some studies confirmed the utility of adjuvant HAIC after hepatic resection for highly malignant HCC (25-27).

In this study, we used two protocols for HAIC that can provide equivalent therapeutic effects (24). Cisplatin and 5-FU are essential in both regimens and are known to have favorable effects on HCC, especially when administered via HAIC (42-44). Cisplatin has a synergistic effect and acts as a modulator on 5-FU. Our second protocol from 2007 comprised two cycles of one-shot HAIC that included cisplatin $\left(60 \mathrm{mg} / \mathrm{mm}^{2}\right)$ and 5 -FU $\left(600 \mathrm{mg} / \mathrm{mm}^{2}\right)$ followed by mild TACE using mitomycin-C $\left(3 \mathrm{mg} / \mathrm{mm}^{2}\right)$ with DSMs. DSMs were added due to their transient occlusive effects which improve drug concentrations within the tumor (45). Adjuvant HAIC should be started within a month after hepatectomy and repeated twice at 1-month intervals. This is a simple and safe 

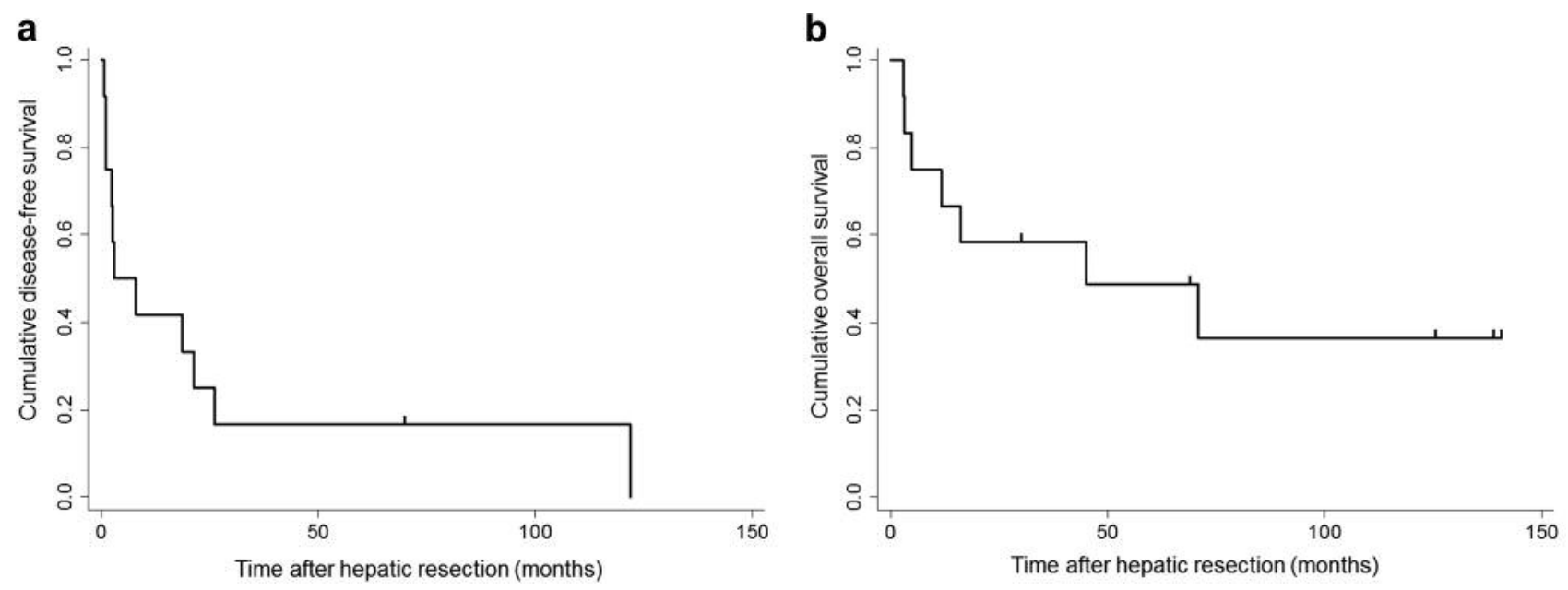

Figure 1. Cumulative survival curves of disease-free $(a)$ and overall $(b)$ survival after hepatic resection for all 12 patients with hepatocellular carcinoma with intrahepatic dissemination undergoing hepatic resection.

a

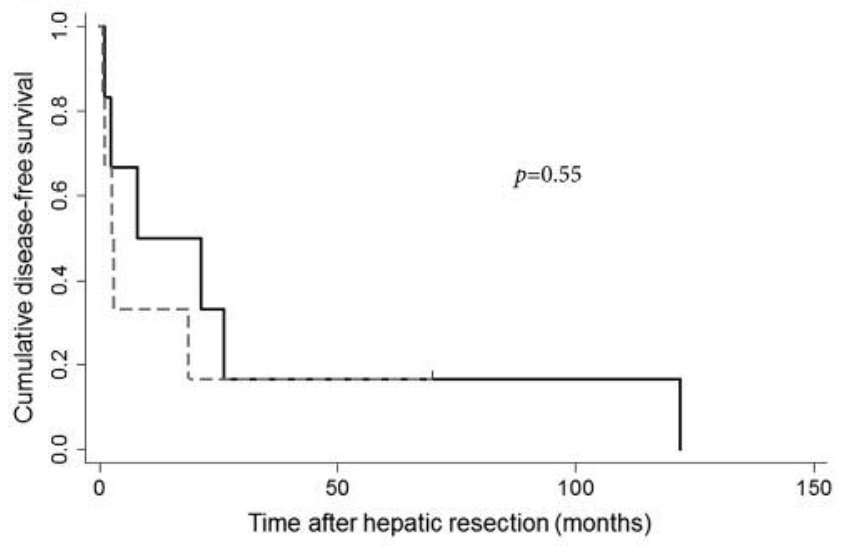

b

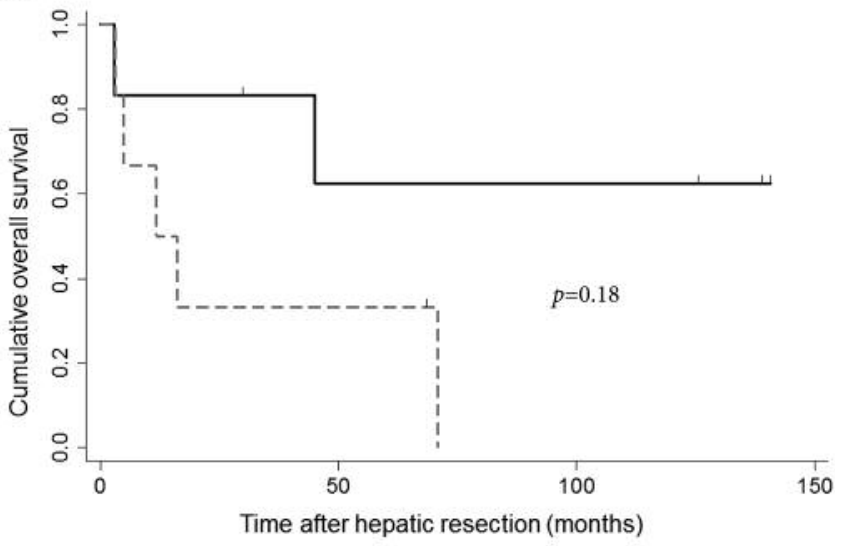

Figure 2. Cumulative survival curves of disease-free $(a)$ and overall $(b)$ survival after hepatic resection for all 12 patients with hepatocellular carcinoma with intrahepatic dissemination undergoing hepatic resection according to therapy with hepatic arterial infusion chemotherapy (solid line: with, dashed line: without).

method that has similar effects to the former HAIC protocol of low-dose cisplatin plus 5-FU with an implanted port (24). More recently, a report suggested that sorafenib plus HAIC with cisplatin can provide a more favorable OS compared to sorafenib alone in patients with advanced HCC (46). In patients with HCC, circulating tumor cells can be detected in the early period after surgery and are a predictor of poor outcomes (47-50); therefore, starting HAIC within 1 month after surgery is essential. Appropriate surgical techniques are required to achieve early induction of adjuvant HAIC.

There are some limitations of our study. This was a retrospective single-center study that enrolled a small number of patients. Data were collected only from patients with resectable HCC with IHD. The non-HAIC group included patients with early recurrence, comorbidities, and poor performance. Therefore, there may have been some selection bias. Nevertheless, despite the severity of HCC in patients with IHD, three out of six patients remained alive more than 5 years after hepatectomy. IHD is a limited condition and may decrease annually because some studies have recommended LAT be avoided for patients with HCC at high risk of IHD (7-14). Further prospective, larger studies will be required to validate these results.

In conclusion, hepatic resection followed by short-term adjuvant HAIC can provide a favorable long-term prognosis for patients with HCC with IHD. 


\section{Disclosure}

The Authors declare no conflict of interest in regard to this study.

\section{Acknowledgements}

The Authors give special thanks to the colleagues of the Department of Gastroenterological Surgery, Kumamoto University for their tremendous contribution to data collection.

\section{References}

1 Livraghi T: Radiofrequency ablation, PEIT and TACE for hepatocellular carcinoma. J Hepatobiliary Pancreat Surg 10: 67-76, 2003

2 Omata M, Tateishi R, Yoshida H and Shiina S: Treatment of hepatocellular carcinoma by percutaneous tumor ablation methods: ethanol injection therapy and radiofrequency ablation. Gastroenterology 127: S159-166, 2004.

3 Lau WY, Leung TW, Yu SC and Ho SK: Percutaneous local ablative therapy for hepatocellular carcinoma: a review and look into the future. Ann Surg 237: 171-179, 2003.

4 Lencioni R: Loco-regional treatment of hepatocellular carcinoma: Hepatology 52: 762-763, 2010.

5 Shiina S, Tateishi R, Arano T, Uchino K, Enooku K, Nakagawa H, Asaoka Y, Sato T, Masuzaki R, Kondo Y, Goto T, Yoshida H, Omata $\mathrm{M}$ and Koike $\mathrm{K}$ : Radiofrequency ablation for hepatocellular carcinoma: 10-year outcome and prognostic factors. Am J Gastroenterol 107: 569-577, 2012.

6 Doi K, Beppu T, Ishiko T, Chikamoto A, Hayashi H, Imai K, Nitta H, Baba Y, Masuda T, Okabe K, Kuramoto M, Kudo K, Okada K, Ohchi T, Takamoti H, Kikuchi K and Baba H: Endoscopic radiofrequency ablation in elderly patients with hepatocellular carcinoma. Anticancer Res 35: 3033-3040, 2015.

7 Seki T, Tamai T, Ikeda K, Imamura M, Nishimura A, Yamashiki $\mathrm{N}$, Nakagawa $\mathrm{T}$ and Inoue K: Rapid progression of hepatocellular carcinoma after transcatheter arterial chemoembolization and percutaneous radiofrequency ablation in the primary tumour region. Eur J Gastroenterol Hepatol 13: 291-294, 2001.

8 Mulier S, Mulier P, Ni Y, Miao Y, Dupas B, Marchal G, Dewerer $\mathrm{Y}$ and Michel L: Complications of radiofrequency coagulation of liver tumours. Br J Surg 89: 1206-1222, 2002.

9 Takada Y, Kurata M and Ohkohchi N: Rapid and aggressive recurrence accompanied by portal tumor thrombus after radiofrequency ablation for hepatocellular carcinoma. Int J Clin Oncol 8: 332-335, 2003.

10 Ruzzenente A, Manzoni GD, Molfetta M, Pachera S, Genco B, Donataccio M, Guqlielmi A: Rapid progression of hepatocellular carcinoma after radiofrequency ablation. World J Gastroenterol 10: 1137-1140, 2004.

11 Nicoli N, Casaril A, Abu Hilal M, Mangiante G, Marchiori L, Ciola M, Inrermizzi L, Campaqnaro T and Mansueto G: A case of rapid intrahepatic dissemination of hepatocellular carcinoma after radiofrequency thermal ablation. Am J Surg 188: 165-167, 2014.

12 Kotoh K, Enjoji M, Arimura E, Morizono S, Kohjima M, Sakai $\mathrm{H}$ and Nakamata $\mathrm{M}$ : Scattered and rapid intrahepatic recurrences after radiofrequency ablation for hepatocellular carcinoma. World J Gastroenterol 11: 6828-6832, 2005.

13 Masuda T, Beppu T, Ishiko T, Horino K, Baba Y, Mizumoto T, Hayashi H, Okabe H, Holad H, Doi K, Okabe K, Takamori H, Hirota $\mathrm{M}$, Iyama $\mathrm{K}$ and Baba $\mathrm{H}$ : Intrahepatic dissemination of hepatocellular carcinoma after local ablation therapy. J Hepatobiliary Pancreat Surg 15: 589-595, 2008.

14 Mori Y, Tamai H, Shingaki N, Moribata K, Shiraki T, Deguchi H,Ueda K, Enomoto S, Magari M, Inoue I, Maekita T, Iguchi M, Yanaoka K, Oka M and Ichinose M: Diffuse intrahepatic recurrence after percutaneous radiofrequency ablation for solitary and small hepatocellular carcinoma. Hepatol Int 3: 509-515, 2009.

15 Imamura J, Tateishi R, Shiina S, Goto E, Sato T, Ohki T, Masuzaki R, Goto T, Yoshida H, Kanai F, Haramura K, Yoshida H and Omata M: Neoplastic seeding after radiofrequency ablation for hepatocellular carcinoma. Am J Gastroenterol 103: 3057-3062, 2008.

16 Shirai K, Tamai H, Shingaki N, Mori Y, Moribata K, Enomoto S, Deguti H, Ueda K, Maekita T, Inoue I, Iguchi M, Yanaoka K, Oka $\mathrm{M}$ and Ichinose $\mathrm{M}$ : Clinical features and risk factors of extrahepatic seeding after percutaneous radiofrequency ablation for hepatocellular carcinoma. Hepatol Res 41: 738-745, 2011.

17 Koda M, Murawaki Y, Hirooka Y, Kitamoto M, Ono M, Sakaeda H, Joko K, Sato S, Tamaki K, Yamasaki T, Shibata H, Shimoe T, Matsuda N, Toshikuri N, Fujuka S, Ohmoto K, Nakamura S, Kariyama K, Aikata H, Kobayashi $\mathrm{Y}$ and Tsutsui A: Complications of radiofrequency ablation for hepatocellular carcinoma in a multicenter study: an analysis of 16346 treated nodules in 13,283 patients. Hepatol Res 42: 1058-64, 2012.

18 Imai K, Beppu T, Chikamoto A, Mima K, Okabe H, Hayashi H, Nitta $H$, Ishiko $T$ and Baba $H$ : Salvage treatment for local recurrence of hepatocellular carcinoma after local ablation therapy. Hepatol Res 44: E335-345, 2014.

19 Yamashita S, Aoki T, Inoue Y, Kaneko J, Sakamoto Y, Sugawara Y, Hasegawa K and Kokudo N: Outcome of salvage hepatic resection for recurrent hepatocellular carcinoma after radiofrequency ablation therapy. Surgery 157: 463-472, 2015.

20 Choi KK, Kim SH, Choi SB, Lim JH, Choi GH, Choi JS and Kim KS: Portal venous invasion: the single most independent risk factor for immediate postoperative recurrence of hepatocellular carcinoma. J Gastroenterol Hepatol 26: 1646-1651, 2011.

21 Ikai I, Yamaoka Y, Yamamoto Y, Ozaki N, Sakai Y, Satoh S, Shinkura N and Yamamoto M: Surgical intervention for patients with stage IV-A hepatocellular carcinoma without lymph node metastasis: proposal as a standard therapy. Ann Surg 227: 433439, 1998.

22 Katagiri S and Yamamoto M: Multidisciplinary treatments for hepatocellular carcinoma with major portal vein tumor thrombus. Surg Today 44: 219-226, 2014.

23 Kokudo T, Hasegawa K, Matsuyama Y, Takayama T, Izumi N, Kadoya M, Kudo M, Ku Y, Sakamoto M, Nakashima O, Kaneko S, and Kokudo N: Liver Cancer Study Group of Japan. Survival benefit of liver resection for hepatocellular carcinoma associated with portal vein invasion. J Hepatol 65: 938-943, 2016.

24 Nitta H, Beppu T, Imai K, Hayashi H, Chikamoto A and Baba $\mathrm{H}$ : Adjuvant hepatic arterial infusion chemotherapy after hepatic resection of hepatocellular carcinoma with macroscopic vascular invasion. World J Surg 37: 1034-1042, 2013.

25 Huang YH, Wu JC, Lui WY, Chau GY, Tsay SH, Chiang JH, King KL, Huo TI, Chang FY and Lee SD: Prospective casecontrolled trial of adjuvant chemotherapy after resection of hepatocellular carcinoma. World J Surg 24: 551-555, 2002.

26 Fukuda S, Okuda K, Imamura M, Imamura I, Eriguchi N and Aoyagi S: Surgical resection combined with chemotherapy for advanced hepatocellular carcinoma with tumor thrombus: report of 19 cases. Surgery 131: 300-310, 2002. 
27 Nagano H, Miyamoto A, Wada H, Ota H, Marubashi S, Takeda Y, Dono K, Umeshita K, Sakon M and Monden M: Interferonalpha and 5-fluorouracil combination therapy after palliative hepatic resection in patients with advanced hepatocellular carcinoma, portal venous tumor thrombus in the major trunk and multiple nodules. Cancer 110: 2493-2501, 2007.

28 Ikai I, Takayasu K, Omata M, Okita K, Nakanuma Y, Matsuyama Y, Makuuchi M, Kojiro M, Ichida T, Arii S and Yamaoka Y: Liver Cancer Study Group of Japan. A modified Japan Integrated Stage score for prognostic assessment in patients with hepatocellular carcinoma. J Gastroenterol 41: 884-892, 2006.

29 Hayashi H, Beppu T, Okabe H, Kuroki H, Nakagawa S, Imai K, Nitta $\mathrm{H}$, Chikamoto A, Ishiko $\mathrm{T}$ and Baba $\mathrm{H}$ : Functional assessment versus conventional volumetric assessment in the prediction of operative outcomes after major hepatectomy. Surgery 157: 20-26, 2015.

30 Ishiko T, Inomata Y, Beppu T, Asonuma K, Okajima H, Takeiti T, Tikamoto A, Yamamoto $\mathrm{H}$ and Baba $\mathrm{H}$ : An improved technique for liver transection using a new device for soft coagulation in living donor hepatectomy. Hepatogastroenterology 59: 1907-1910, 2012.

31 Inoue Y, Hasegawa K, Ishizawa T, Aoki T, Sano K, Beck Y, Imamura H, Sugawara Y, Kokudo N and Makuuchi M: Is there any difference in survival according to the portal tumor thrombectomy method in patients with hepatocellular carcinoma? Surgery 145: 9-19, 2009.

32 Imai K, Beppu T, Chikamoto A, Doi K, Okabe H, Hayashi H, Nitta H, Ishiko T, Takamori $\mathrm{H}$ and Baba $\mathrm{H}$ : Comparison between hepatic resection and radiofrequency ablation as first-line treatment for solitary small-sized hepatocellular carcinoma of 3 cm or less. Hepatol Res 43: 853-864, 2013.

33 Kudo M, Ueshima K, Kubo S, Sakamoto M, Tanaka M, Ikai I, Furuse J, Murakami T, Kadoya M and Kokudo N: Liver Cancer Study Group of Japan. Response Evaluation Criteria in Cancer of the Liver (RECICL) (2015 Revised version). Hepatol Res 46: 3-9, 2016.

34 Beppu T, Ohara C, Yamaguchi Y, Ichihara T, Yamanaka T, Katafuchi S, Katafuchi S, Ikei S, Mori K, Fukushima S and Nakano M: A new approach to chemoembolization for unresectable hepatocellular carcinoma using aclarubicin microspheres in combination with cisplatin suspended in iodized oil. Cancer 68 : 2555-2560, 1991.

35 Yu HC, Cheng JS, Lai KH, Lin CP, Lo GH, Lin CK, Hsu PI, Chan HH, Lo CC, Tsai WL and Chen WC: Factors for early tumor recurrence of single small hepatocellular carcinoma after percutaneous radiofrequency ablation therapy. World J Gastroenterol 11: 1439-1444, 2005.

36 Harrison LE, Koneru B, Baramipour P, Fisher A, Barone A, Wilson D, Dela Torre A, Cho KC, Contractor D and Korogodsky $\mathrm{M}$ : Locoregional recurrences are frequent after radiofrequency ablation for hepatocellular carcinoma. J Am Coll Surg 197: 759764, 2003.

37 Arii S, Teramoto K, Kawamura T, Okamoto H, Kaido T, Mori A and Imamura M: Characteristics of recurrent hepatocellular carcinoma in Japan and our surgical experience. J Hepatobiliary Pancreat Surg 8: 397-403, 2001.

38 Mima K, Okabe H, Ishimoto T, Hayashi H, Nakagawa S, Kuroki H, Watanabe M, Beppu T, Tamada M, Nagano O, Saya H and Baba H: CD44s regulates the TGF-beta-mediated mesenchymal phenotype and is associated with poor prognosis in patients with hepatocellular carcinoma. Cancer Res 72: 3414-3423, 2012.
39 Chen X, Lingala S, Khoobyari S, Nolta J, Zern MA and Wu J: Epithelial mesenchymal transition and hedgehog signaling activation are associated with chemoresistance and invasion of hepatoma subpopulations. J Hepatol 55: 838-845, 2011.

40 Mima K, Hayashi H, Imai K, Kuroki H, Nakagawa S, Okabe H, Chikamoto A, Watanabe M, Beppu T and Baba H: High CD44s expression is associated with the EMT expression profile and intrahepatic dissemination of hepatocellular carcinoma after local ablation therapy. J Hepatobiliary Pancreat Sci 20: 429-434, 2013.

41 Yamada S, Utsunomiya T, Morine Y, Imura S, Ikemoto T, Arakawa Y, Kanamoto M, Iwahashi S, Saito Y, Takasu C, Ishikawa D and Shimada M: Expressions of hypoxia-inducible factor-1 and epithelial cell adhesion molecule are linked with aggressive local recurrence of hepatocellular carcinoma after radiofrequency ablation therapy. Ann Surg Oncol 21 Suppl: S436-442, 2014.

42 Shimada M, Takenaka K, Kawahara N, Yamamoto K, Shirabe K, Maehara Y and Sugimachi K: Chemosensitivity in primary liver cancers: evaluation of the correlation between chemosensitivity and clinicopathological factors. Hepatogastroenterology 43: 1159-1164, 1996.

43 Hoshida Y, Moriyama M, Otsuka M, Kato N, Goto T, Taniguchi $\mathrm{H}$, Shiratori Y, Seki N and Omata M: Identification of genes associated with sensitivity to 5-fluorouracil and cisplatin in hepatoma cells. J Gastroenterol 37(Suppl 14): 92-95, 2002.

44 Furukawa S: In vitro chemosensitivity of hepatocellular carcinoma for hepatic arterial infusion chemotherapy using the MTT assay with the combinations of antitumor drugs. Kurume Med J 25: 2533, 2004.

45 Ishida K, Hirooka M, Hiraoka A, Kumagi T, Uehara T, Hiasa Y, Horiike $\mathrm{N}$ and Onji M: Treatment of hepatocellular carcinoma using arterial chemoembolization with degradable starch microspheres and continuous arterial infusion of 5-fluorouracil. Jpn J Clin Oncol 38: 596-603, 2008.

46 Ikeda M, Shimizu S, Sato T, Morimoto M, Kojima Y, Inaba Y, Hagihara A, Kudo M, Nakamori S, Kaneko S, Sugimoto R, Tahara T, Ohmura T, Yasui K, Sato K, Ishii H, Furuse J and Okusaka T: Sorafenib plus hepatic arterial infusion chemotherapy with cisplatin versus sorafenib for advanced hepatocellular carcinoma: randomized phase II trial. Ann Oncol 27: 2090-2096, 2016.

47 Li QG, Yang GS, Yang Q, Wei LX, Yang N, Zhou XP and Jia FQ: Disseminated tumor cells homing into rats' liver: a new possible mechanism of HCC recurrence. World J Gastroenterol 10: 903905, 2005.

48 Sun YF, Xu Y, Yang XR, Guo W, Zhang X, Qiu SJ, Shi RY, Hu B, Zhou J and Fan J: Circulating stem cell-like epithelial cell adhesion molecule-positive tumor cells indicate poor prognosis of hepatocellular carcinoma after curative resection. Hepatology 57: 1458-1468, 2013.

49 Zhang Y, Shi ZL, Yang X and Yin ZF: Targeting of circulating hepatocellular carcinoma cells to prevent postoperative recurrence and metastasis. World J Gastroenterol 20: 142-147, 2014.

50 Okabe H, Ishimoto T, Mima K, Nakagawa S, Hayashi H, Kuroki H, Imai K, Nitta H, Saito S, Hashimoto D, Chikamoto A, Ishiko T, Watanabe M, Nagano O, Beppu T, Saya H and Baba H: CD44s signals the acquisition of the mesenchymal phenotype required for anchorage-independent cell survival in hepatocellular carcinoma. Br J Cancer 110: 958-966, 2014.

Received October 23, 2017

Revised November 9, 2017

Accepted November 10, 2017 